\title{
EL FINAL DE LA VIDA A LOS VEINTE AÑOS \\ DE JURISPRUDENCIA DEL TRIBUNAL EUROPEO DE DERECHOS HUMANOS ${ }^{1}$ \\ The end of life after 20 years of European Court of Human Rights jurisprudence \\ UGO ADAMO ${ }^{2}$ \\ Universidad de Calabria, IT \\ ugo.adamo@unical.it
}

\section{Resumen}

El presente trabajo analiza la jurisprudencia del Tribunal Europeo de Derechos Humanos sobre la amplia temática del final de la vida. La jurisprudencia del Tribunal Europeo de Derechos Humanos, que tiene su leading-case en la conocida sentencia Pretty y que reconoce un amplio margen de apreciación en relación con estos temas, empieza a tomar en consideración no solo el art. 2 (derecho a la vida), sino también el art. 8 (calidad de vida), una disposición que protege el derecho a elegir cuándo y cómo morir.

La jurisprudencia europea demuestra que se está produciendo un «cambio de perspectiva» en el análisis de las prácticas eutanásicas que, en caso de someterlas a examen, resultan conformes al derecho a la vida si su ejercicio se somete a limitaciones y a procedimientos que protejan a las personas vulnerables.

1 Traducido del italiano por Claudio di Maio, Universidad de Calabria.

2 Este artículo está dedicado a la memoria del profesor Pablo Pérez Tremps. 


\section{Palabras clave}

Jurisprudencia del Tribunal Europeo de Derechos Humanos; derecho a morir; prácticas eutanásicas; rechazo de tratamiento; margen de apreciación.

\section{Abstract}

This essay analyzes the contribution of the jurisprudence of the European Court of Human Rights to the broad theme of the end of life. Conventional jurisprudence, which has its leading-case in the well-known judgment Pretty and which recognizes a wide margin of appreciation in relation to these issues, begins to take into account only article 2 (right to life) now see in article 8 (quality of life) a provision that protects the right to choose when and how to die.

European jurisprudence demonstrates that there is a "change in perspective» in the analysis of euthanasic practices that, if submitted for examination, are in conformity with the right to life if their exercise is subject to limitations and procedures that protect the vulnerable people

\section{Keywords}

Jurisprudence of the European Court of Human Rights; right to die; euthanasic practices; refusal of treatment; margin of appreciation. 


\section{Sumario}

I. PREMISA. II. EL ART. 2 DEL CONVENIO EUROPEO PARA LA PROTECCIÓN DE LOS DERECHOS HUMANOS Y DE LAS LIBERTADES FUNDAMENTALES (CEDH) NO RECONOCE NINGÚN DERECHO A MORIR. III. EL ART. 8 \& 1 DEL CEDH INCLUYE EL DERECHO DE UNA PERSONA A DECIDIR CÓMO Y EN QUÉ MOMENTO PONER FIN A SU VIDA. IV. LAS NORMAS PARA LA SOLICITUD DE PRÁCTICA EUTANÁSICA DEBEN SER SIEMPRE CLARAS Y TRANSPARENTES. V. LA INTERRUPCIÓN DE LOS TRATAMIENTOS QUE SALVAN LA VIDA CUANDO DERIVAN DE UNA OBSTINACIÓN IRRAZONABLE. VI. CONCLUSIONES. BIBLIOGRAFÍA.

\section{PREMISA}

El objetivo de este estudio es analizar y hacer un balance de la jurisprudencia del Tribunal de Estrasburgo sobre la conformidad con el Convenio Europeo para la Protección de los Derechos Humanos y de las Libertades Fundamentales $(\mathrm{CEDH})$ del reconocimiento (pero también de la falta de regulación) de prácticas eutanásicas en los ordenamientos estatales que forman parte del Convenio. Otro objetivo es evidenciar las conclusiones a las que llegó el Tribunal Europeo de Derechos Humanos (TEDH) -incluso con el fin de comprender las diferencias de las prácticas de eutanasia- en relación con la interrupción del tratamiento por parte de un paciente cuyo cuadro diagnóstico debe considerarse como tratamientos terapéuticos de los que no cabe esperar razonablemente una recuperación ni una mejora de la calidad de vida.

Sin embargo, antes de proceder, es metodológicamente correcto dar una definición de la eutanasia o al menos especificar su significado — teniendo en cuenta sus múltiples usos- que se utilizará en esta contribución. Mientras tanto, es más que apropiado marcar la diferencia entre la eutanasia «activa» y la "pasiva», con el fin de evitar el uso de este último término para indicar el rechazo de un tratamiento (ya iniciado) para salvar vidas. Y, de hecho, aunque en ambos casos la petición de poner fin a la propia existencia proceda del paciente, la respuesta del operador médico es profundamente diferente en las dos situaciones, puesto que depende de propósitos diferentes. En el primer caso, el objetivo de la actuación médica es causar la muerte, anticipando la evolución de la enfermedad; en el segundo caso, en cambio, se trata de dar seguimiento a una solicitud de suspensión del tratamiento, permitiendo el curso de la enfermedad que dará lugar «naturalmente» a la muerte. El fundamento de la solicitud de eutanasia es la 
búsqueda de una muerte benéfica proporcionada por otros a quienes sufren una enfermedad incurable con un resultado letal, previa solicitud válida, para poner fin a un estado de sufrimiento considerado inútil e intolerable por el paciente.

Tal como se adelantó, las definiciones que pueden darse de la eutanasia son diferentes, múltiples y no siempre las mismas, pero —aquí- solo se toman en consideración las que se derivan principalmente del principio de la libre determinación ${ }^{3}$. Por lo tanto, para razonar jurídicamente sobre esta noción, el núcleo esencial de los elementos que deben constituir su definición se puede resumir de la siguiente manera: 1 . solicitud consciente y libre del sujeto enfermo; 2 . expresión del principio personalista y libre autodeterminación del sujeto solicitante; 3. alcance de un estado de enfermedad tan grave que se pueda definir como irreversible y que conlleve la no aceptación de la vida por parte de (y solo por parte de) la persona que solicita la eutanasia. Por lo tanto, con respecto a todo lo dicho, solo se pretende tomar en consideración — como se verá más adelante- las prácticas que forman parte de la categoría de la asistencia médica a la muerte, excluyendo las hipótesis de eutanasia no solicitada, es decir, en ausencia de una solicitud de las personas que no están en condiciones de realizarla (lactantes con discapacidades graves, personas que viven en una situación de inconsciencia e irreversibilidad de la enfermedad y que no han suscrito las disposiciones de tratamiento anticipado).

El Tribunal Europeo ha tenido ocasión de dictar varias decisiones que han sido objeto de juicio (directa o indirectamente): el derecho a decidir si querer morir y la posibilidad de identificar una protección implícita en el CEDH. El Tribunal ampliará el contenido del derecho previsto en el artículo 8 del Convenio Europeo de Derechos Humanos, que protege el derecho al respeto de la vida privada y familiar, ya que también incluirá la protección de la calidad de vida. El Tribunal logrará así proteger a los que piden poner fin a los sufrimientos del cuerpo (en el que se les «obliga a vivir») y no a los del alma. Sin esta evolución interpretativa, como veremos, no se garantizaría la protección a todos aquellos pacientes que se encuentran en una condición en la que hace solo unas décadas era inimaginable encontrarse, en una época en la que la tecnología todavía no era tan intrusiva.

3 A su vez, las prácticas de eutanasia se distinguen entre la ayuda al suicidio y el asesinato consentido. La ayuda al suicidio se refiere a la circunstancia de que la muerte es consecuencia de un acto suicida, aunque se haya cometido con la ayuda de un tercero, ya que el interesado no está en condiciones de cometerlo de forma independiente. La ayuda solicitada, por lo tanto, es preparatoria para la realización del «último» gesto, que en cualquier caso se cumple con el suicidio. La asunción de una dosis letal mediante la auto-inyección, por parte de un enfermo terminal, de una droga prescrita e indicada en la dosis necesaria por un médico, significa que este ayuda a suicidarse sin cometer ningún asesinato, como sería el caso si la inyección de la droga letal la realizara el propio médico a petición del paciente. Las hipótesis, por lo tanto, son diferentes si se mira al sujeto que actúa en última instancia para procurar la muerte de sí mismo (ayuda al suicidio) o de otros (eutanasia directa activa). 
Más allá de lo que sucede en algunos países en los que existe una disciplina legislativa sobre cómo y cuándo poder decidir activamente sobre la interrupción de la vida, no existe un idem sentire en las legislaciones europeas 4 . Ante este estado de cosas, se entiende la dirección de autocontención, que ha caracterizado la jurisprudencia del TEDH sobre el tema hasta hoy.

La primera vez que el Tribunal de Estrasburgo se pronunció sobre un tema relacionado con el fin de la vida fue en el caso Sanles c. España $a^{5}$. Ramón Sampedro era un ciudadano español que padeció una grave discapacidad (tetraplejia) como consecuencia de lesiones irreversibles de la médula espinal causadas por un accidente. Desde hacía varios años el señor Sampedro había solicitado a los jueces españoles que no procesasen al sujeto que le ayudara a morir, según él dignamente, para cumplir su voluntad. Una vez agotados los recursos de apelación, en espera de la resolución del recurso de amparo interpuesto ante el Tribunal Constitucional de España, el demandante falleció por suicidio asistido con ayuda de sujetos desconocidos.

Mientras la justicia iniciaba un juicio penal contra desconocidos, la cuñada de Sampedro, la señora Sanles Sanles, proseguía con el juicio iniciado por su cuñado. Sin embargo, esa reclamación no prosperó, ya que el Tribunal español consideró que la demandante no estaba legitimada para proseguir (o iniciar) un procedimiento para la protección de un derecho que es personalísimo y no transmisible.

La demandante, en ese momento, acudió al TEDH, alegando la violación del Convenio Europeo de Derechos Humanos y argumentando que la no previsión en el ordenamiento jurídico español de la legalidad de la práctica de la eutanasia (o sea, ayuda al suicidio) y, por ende, la violación del art. 2 del CEDH que, al proteger el derecho a la vida, reconoce también el derecho a morir con dignidad, siendo este último un derecho «espejo» del primero.

El Tribunal Europeo, sin entrar en el asunto, declaró la acción inadmisible porque la recurrente no era una "víctima» en el sentido del art. 34 del Convenio Europeo de Derechos Humanos, ya que no estaba directamente afectada por las

$4 \quad$ Entre los 42 países que se adhieren al CEDH, una legislación sobre la eutanasia existe solo en Suiza, Países Bajos, Bélgica y Luxemburgo. Para el caso italiano (que reconoce parcialmente la ayuda al suicidio), cfr. Corte const., sent. n. 242/2019. Véanse Poli (2020: 1 ss.) y Malfatti (2019: 1 ss.). En España está en discusión avanzada un proyecto para aprobar la ley sobre la ayuda a morir en este mismo año. El Tribunal Constitucional alemán también ha intervenido recientemente sobre el suicidio asistido (Bundesverfassungsgericht, sentencia de 26 de febrero de 2020): Fiano (2020: 1 ss.) y Casonato (2020: 15 ss.). El estudio permitirá también valorar positivamente la reciente ley española (Ley Orgánica $3 / 2021$, de 24 de marzo, de regulación de la eutanasia), puesto que esta ley, encuadrada dentro de los modelos permisivos, supone una regulación procesalmente clara, hasta el punto de ser conforme (como subrayaremos) con la jurisprudencia del Tribunal Europeo.

5 Tribunal Europeo de Derechos Humanos, Sección 4a 26 de octubre de 2000 (caso Sanles c. Spagna). 
medidas impugnadas y porque el derecho invocado era un derecho muy personal $y$, por lo tanto, no era transferible a otros ${ }^{6}$.

Si bien esta es la primera decisión a la que hay que referirse, el leading-case de la corriente jurisprudencial del que seguramente se van a trazar las líneas es el conocido caso de Diane Pretty ${ }^{7}$. Por la relevancia de esta decisión, pero también porque subraya la naturaleza casuística de la jurisprudencia del $\mathrm{CEDH}$, es oportuno reconstruir dicho asunto procesal.

\section{EL ART. 2 DEL CONVENIO EUROPEO PARA LA PROTECCIÓN DE LOS DERECHOS HUMANOS Y DE LAS LIBERTADES FUNDAMENTALES (CEDH) NO RECONOCE NINGÚN DERECHO A MORIR}

Diane Pretty era una mujer británica de 43 años a quien se le diagnosticó una enfermedad neurodegenerativa progresiva (esclerosis lateral amiotrófica: ELA). Debido al empeoramiento de su enfermedad, la señora Pretty había remitido el asunto al TEDH, que en 2002 dictó una decisión, poco antes del fallecimiento de la demandante por causas naturales.

Según el Tribunal Europeo se comprende perfectamente la dramática situación en la que se encontraba la mujer con una enfermedad:

[...] que afecta a las neuronas motrices del interior del sistema nervioso central y que provoca una alteración gradual de las células que hacen funcionar a los músculos voluntarios del cuerpo [cuya] evolución conduce a un grave debilitamiento de los brazos y de las piernas, así como de los músculos implicados en el control de la respiración. La muerte sobreviene generalmente por problemas de insuficiencia respiratoria y de neumonía debidos a la debilidad de los músculos respiratorios y de aquellos que controlan la voz y la deglución. Ningún tratamiento puede detener la evolución de la enfermedad [...] La señora P. está casi paralizada desde el cuello hasta los pies, no puede prácticamente expresarse de forma comprensible y se le alimenta por medio de una sonda. Su esperanza de vida es muy limitada y se cuenta en meses, o incluso semanas. Su intelecto y su capacidad para tomar decisiones están intactos. La fase final de la enfermedad es extremadamente penosa y lleva consigo una pérdida de dignidad. La señora P. tiene miedo y se lamenta del sufrimiento y de la indignidad que va a tener que soportar si se deja que la enfermedad se desarrolle, y desea por tanto vivamente poder decidir cuándo y cómo morir .

6 Cfr. también, Tribunal Europeo de Derechos Humanos, Sección 2a, 16 de diciembre de 2008, caso Ada Rossi y otros c. Italia.

7 Tribunal Europeo de Derechos Humanos, Sección 4a, 29 de abril de 2002, caso Pretty c. Reino Unido. Véanse Bestagno (2012: 36 ss.) y Tomasi (2012: 297 ss.).

8 Caso Pretty contra Reino Unido, p. ti 7-8. Las decisiones han sido consultadas en www.echr. coe; cuando está disponible nos remitimos a la traducción oficial en lengua española; en caso contrario, nos remitimos a la traducción francesa o, faltando esta última, a la inglesa. 
En Reino Unido, desde 1961, dejó de considerarse un delito el hecho de que una persona cometa suicidio9 (norma inaplicable en las circunstancias del caso, ya que la señora Pretty no estaba físicamente en condiciones de cometerlo). Por el contrario, ayudar a la realización del acto mismo sigue siendo considerado y castigado como delito ${ }^{10}$.

El abogado de la demandante solicitó al Director of Public Prosecutions (DPP) que no procesara penalmente al marido de su cliente, quien, conforme a la voluntad de su esposa, deseaba ayudarle a cumplir su deseo de suicidarse. El DPP se negó a aceptar lo que parecía ser una solicitud de inmunidad. El abogado se dirigió entonces al Tribunal Superior en primera instancia, que a su vez rechazó la solicitud, y luego a la House of Lords (juez de última instancia), que también confirmó su desestimación. Una vez agotados los recursos internos, recurrió al TEDH por violación de varios artículos del Convenio. En el recurso se alegaba que el art. 2 del CEDH no solo garantizaba el derecho a la vida, sino también el derecho a elegir entre seguir viviendo o dejar de vivir. Esta decisión corresponde al individuo y es un corolario del mismo derecho a la vida, por lo que se prefigura un verdadero derecho a morir que debe ser reconocido implícitamente para evitar el sufrimiento ineluctable y la prosecución de una existencia no digna.

Según los jueces de Estrasburgo, el art. 2 no puede ser interpretado como otorgamiento de un derecho diametralmente opuesto al derecho consagrado en el texto: es decir, del derecho a la vida no deriva el derecho a morir. En efecto, el art. 2 «protege el derecho a la vida, sin el cual el goce de ninguno de los demás derechos y libertades garantizados por el Convenio sería ilusorio» (\$37). Además, el art. 2 ni siquiera contiene un derecho de autodeterminación tal que todo individuo tenga derecho a elegir la muerte en lugar de la vida $(\$ 40)$.

El Tribunal tampoco da importancia al motivo basado en el art. 3 del Convenio Europeo de Derechos Humanos, relativo al sufrimiento que la recurrente se ve obligada a padecer a causa de la enfermedad, que se considera inhumana y degradante. A este respecto, el Tribunal no tiene ninguna dificultad en señalar que el Estado contra el que se entabla la acción no ha impuesto ningún tratamiento médico a la apelante. De hecho, si bien corresponde a la integridad física y psíquica de la persona poder negarse a un tratamiento (incluso para salvar la vida), en el presente caso se pedía la impunidad de la conducta del marido en caso de violación de una norma penal del derecho nacional, contraria al Convenio.

En cambio, es en relación con otra parte del recurso, relativa a la presunta violación del art. 8 del $\mathrm{CEDH}$, que el Tribunal ofrece una interpretación más que interesante. En el art. 8 se explicita el concepto de «vida privada»; un concepto amplio que puede definirse de la manera más exhaustiva posible. Sin dejar de

9 Suicide Act 1961, sección 1.

10 Ibid., sección 2(1). 
reafirmar el principio de la sacralidad de la vida, como dictan los arts. 2 y 3 del Convenio, el Tribunal observa que:

la noción de calidad de vida toma todo su significado desde el punto de vista del artículo 8. En una época en la que se asiste a una sofisticación médica creciente y a un aumento de la esperanza de vida, muchas personas temen que se les fuerce a mantenerse vivas hasta una edad muy avanzada o en un estado de ruina física o mental en las antípodas de la percepción aguda que ellas tienen de sí mismas y de su identidad personal [...] La demandante en este caso se ve impedida por la Ley para ejercer su elección de evitar lo que, en su opinión, será un final indigno y penoso. El Tribunal no puede excluir que esto representa una vulneración del derecho de la interesada al respeto de su vida privada $(\$ \$ 65-67)$.

Sin embargo, los jueces de Estrasburgo se remiten al razonamiento de la denominada «pendiente resbaladiza» — según el cual, una vez reconocida la licitud de un comportamiento, el mismo no se limitaría a las únicas hipótesis previstas-, hablando (en general) de personas frágiles y reconociendo (en concreto) en la ratio legis de la disposición en cuestión una protección adecuada contra la vulnerabilidad de la categoría a la que pertenecen dichas personas. Se reconoce a los Estados la evaluación del riesgo de abuso y de las probables consecuencias de los excesos que podrían derivarse o que incluso se verían afectados al excluir la prohibición general de la ayuda. Solo el legislador ${ }^{11}$ es competente para limitar al máximo los riesgos de «deslizamiento» que implicaría la legalización solicitada por la demandante.

Efectivamente, el Tribunal Europeo concluye que no se ha producido ninguna violación del art. 8 del $\mathrm{CEDH}$, porque la injerencia del Estado en las decisiones relativas a la terminación de la vida constituye una justificación proporcionada al objetivo de prevenir los riesgos de abuso más que posible contra los actos que tienen por objeto poner fin a la vida misma, en relación a las personas frágiles que padecen enfermedades incurables y que, debido a su condición, se encuentran en una situación especialmente vulnerable.

Mucho más lacónica es la referencia a la supuesta violación del art. 9. Según la demandante, el DPP, rechazando la demanda de que no se persiga al marido que la habría ayudado a suicidarse, vulneró también el derecho de la demandante a la libertad de manifestar sus convicciones. Una vez más, el Tribunal Europeo no reconoce la violación de ningún derecho, porque las alegaciones de la demandante no constituyen ninguna forma de expresión de su pensamiento.

Un último motivo de recurso se basaba en el art. 14 del CEDH, mediante el cual la demandante denunciaba ser víctima de una discriminación, en el sentido

11 «Ahora bien, aunque el artículo 34 del Convenio otorga al Tribunal la misión no de formular opiniones en abstracto, sino de aplicar el Convenio a hechos concretos de los casos que le son sometidos, las sentencias dictadas en los asuntos individuales son desde luego, en mayor o menor medida, precedentes y la decisión en este caso no puede ser articulada, ni en la teoría ni en la práctica, de forma que impida que sea aplicada en otros casos» (\$75). 
de ser tratada como persona que, al no estar afectada por una minusvalía física, habría podido procurarse el suicidio por sí misma; mientras ella, aun queriendo, no podía suicidarse sin ayuda ${ }^{12}$.

Según el Tribunal Europeo, que también declaró esta tesis infundada, no existe violación del principio de no discriminación entre las personas que son capaces de suicidarse sin ayuda y las que no son capaces de hacerlo: «[l]a frontera entre las dos categorías es a menudo estrecha, y tratar de inscribir en la Ley una excepción para las personas que se consideran no son capaces de suicidarse, debilitaría seriamente la protección de la vida que la Ley de 1961 ha pretendido consagrar y aumentaría de forma significativa el riesgo de abuso» (\$89).

$\mathrm{Si}$, por un lado, esta significativa decisión del Tribunal de Estrasburgo ${ }^{13}$ considera que la legislación británica es compatible con la del CEDH, por el otro «lanza una señal de posibles "recolocaciones" interpretativas" (D’Aloia, 2012: 16), cuando alude al perfil de la calidad de vida y por ende a una posible protección ex art. 8 (Bifulco, 2003: 167 y s.; De Stefani, 2010: 672 y ss.; Canestrari y Faenza, 2008: 80-82).

\section{EL ART. 8 \& 1 DEL CEDH INCLUYE EL DERECHO DE UNA PERSONA A DECIDIR CÓMO Y EN QUÉ MOMENTO PONER FIN A SU VIDA}

Algunos de los recursos interpuestos después de 2002 se fundamentan en la afirmación de que la dignidad y la libertad del hombre son la esencia misma de

12 Sin embargo, también podría plantearse el caso de que un sujeto solicite la interrupción de un tratamiento que puede salvar su vida para dar lugar a un fin de vida que corresponda a su concepto de dignidad. En la doctrina se habla de una odiosa «sfortuna» Rodotà (2003: 220), de «terribile sfortuna» Tripodina (2004: 128). Un ejemplo de lo que se está diciendo lo reconstruye de manera clara y exhaustiva Casonato (2012: 220-227). A diferencia de D. Pretty, doña B era una mujer tetrapléjica completamente paralizada del cuello para abajo y para poder respirar vivía obligada a utilizar un pulmón de acero; solicitó la interrupción del tratamiento, obtuvo el consentimiento y falleció. Aunque la solicitud de intervención médica fuera diferente, era idéntica la valoración libre y consciente de la indignidad de su existencia y la petición de un acompañamiento a la muerte considerado digno.

13 Mucho más recientemente, se ha dudado que la legislación inglesa cumpliera con la Convención. Si la jurisprudencia que se acaba de comentar se refiere más precisamente al art. 2 del CEDH, el TEDH nuevamente ha tenido que pronunciarse sobre la compatibilidad de la penalización de la ayuda al suicidio y de la eutanasia con el art. 8 CEDH. Para el Tribunal Europeo de Derechos Humanos (caso Nicklinson y Lamb c. Reino Unido del 16 de julio del 2015) los recursos jurisdiccionales internos, que rechazaron los recursos para que se declarara la legislación inglesa contraria al art. $8 \mathrm{CEDH}$, han demostrado — siempre según el TEDH - que la compatibilidad de las leyes internas de los Estados (en el caso que nos interesa se trata de la Section 2 del Suicide Act) con el parámetro convencional debe evaluarse a la luz de la doctrina del margen de apreciación que en esta materia ya se ha observado $(\$ 84)$ y corresponde al Parlamento inglés establecer el equilibrio entre los valores que intervienen $(\$ 85)$. 
la Convención y que la noción de calidad de vida y de autonomía personal están llenas de significado desde el punto de vista del art. $8^{14}$. De hecho, más recientemente, el TEDH ha sido llamado a pronunciarse sobre un asunto relacionado con el final de la vida (Conti, 2012: 555-602), que nació de una cuestión jurídica (totalmente) diferente a la del caso Pretty ${ }^{15}$.

El demandante era un ciudadano suizo (M. Ernest G. Haas) que llevaba veinte años sufriendo una enfermedad muy grave que le hizo creer (como en el caso D. Pretty) que su vida ya no era digna. De los documentos del juicio podemos deducir que ya había intentado en dos ocasiones poner fin a su existencia a través de un intento de suicidio, pero sin éxito.

Entonces, para poner fin a su vida, decidió recurrir a la ayuda ofrecida por una conocida asociación privada que presta asistencia al suicidio mediante la suministración de pentobarbital sódico, un barbitúrico de acción letal rápida. Sin embargo, el demandante no pudo recibir el tratamiento de la asociación Dignitas, ya que la enfermedad que padecía no era una enfermedad considerada terminal, sino que se trataba de un síndrome psiquiátrico, para el cual, a pesar de su estado avanzado, desde el punto de vista médico-científico no podía excluirse la curación.

Aunque Suiza sea uno de los pocos países europeos en los que se reconoce la posibilidad de solicitar y obtener asistencia para el suicidio, no significa que su legalización sea absoluta y generalizada. De hecho, el Código Penal suizo, que sigue prohibiendo el homicidio del consintiente, legitima (solo) la asistencia al suicidio si no hay razones de carácter egoísta ${ }^{16}$ y especifica que el acceso al pentobarbital puede obtenerse solo con prescripción médica.

Volviendo a los hechos, ninguno de los psiquiatras consultados firmó la prescripción médica para suministración de pentobarbital, por lo que el señor Haas decidió dirigirse a varias autoridades, entre ellas la de la Oficina Federal de Salud Pública, la Oficina Federal de Justicia y también el Departamento Federal del Interior, con el fin de obtener la autorización para obtener el fármaco, a través de la asociación Dignitas, incluso sin receta médica. Tampoco esta vía tuvo éxito, hasta el punto de que el ciudadano suizo decidió recurrir al Tribunal Federal denunciando precisamente la violación del art. 8 del CEDH. Según su opinión, por lo que se reconoce en dicho artículo (el derecho a decidir sobre su propio fallecimiento), no se aplican en el caso de quo las excepciones indicadas para legitimar la injerencia del Estado, que solo puede limitar el derecho en sí mismo, así como el previsto por el segundo apartado del mismo art. 8 .

El señor Haas argumentó que la obligación de prescripción médica para obtener la sustancia necesaria para el suicidio y el no poder obtener dicha

\footnotetext{
14 Tal como ha sido establecido, aunque sea en un obiter dictum, en Pretty, $\$ 65$.

15 Tribunal Europeo de Derechos Humanos, Sección 1a, 28 de enero de 2011, caso Haas $c$. Suiza. Véanse Butturini (2011: 1 y ss.); Zanichelli (2011: 1 y ss.); Conti (2013: 260).

16 Art. 114 del código penal suizo.
} 
prescripción constituían una restricción ilegítima (por parte del Estado) del derecho al respeto de la propia vida.

También el Tribunal Federal rechazó el recurso, considerando, en primer lugar, que el asunto no se ajustaba a los casos excepcionales en los que el fármaco podía entregarse sin receta y que derecho a la autodeterminación disciplinado por el art. $8 \$ 1$ del CEDH incluye la libertad de un individuo a decidir cómo y cuándo poner fin a su vida, aunque sea distinto del derecho a la asistencia al suicidio, proporcionada por el Estado o por un tercero.

Una vez agotados todos los recursos internos, el demandante acudió al TEDH, alegando la violación del art. 8 del Convenio y, por tanto, la injerencia del Estado en el derecho al respeto de su vida, dado que, en un caso excepcional como el suyo, el Estado debía garantizar la posibilidad de obtener los medicamentos necesarios para el suicidio.

Deben destacarse las diferencias reales que existen entre este caso y el de Pretty c. Reino Unido, en el que la demandante, que padecía una enfermedad grave e incurable, se encontraba en una situación de incapacidad para suicidarse si alguien no la ayudaba, por lo tanto, no podía acabar con su existencia, aunque su vida ya no correspondiera a su idea de dignidad humana.

Por el contrario, en el caso Haas, la enfermedad del demandante -clasificada como curable - no le impedía actuar por sí mismo para procurarse la muerte. Por lo tanto, es necesario comprender si en el derecho a la autodeterminación, garantizado por el art. $8 \$ 1$, está contemplado también el derecho de una persona a recibir ayuda para el suicidio — siempre y en cualquier casoindependientemente de que subsistan determinadas circunstancias y, por lo tanto, sin condición alguna.

La afirmación de que toda persona tiene derecho a decidir cómo y en qué momento poner fin a su vida - con el límite insuperable de que dicha voluntad se formule de manera libre- era uno de los aspectos del derecho al respeto de su vida privada $(\$ 51)$ que se afirmó también en el caso Pretty (\$ 67); según el Tribunal de Estrasburgo, la necesidad absoluta de la prescripción médica para poder conceder el pentobarbital es una forma adecuada y necesaria para proteger la vida de las personas vulnerables, cuya intención de suicidio también puede basarse en una crisis temporal, capaz de limitar su capacidad de discernimiento.

Aunque la noción de "vida privada» es bastante amplia, la protección del derecho convencional no requiere que el Estado cargue con la obligación de autorizar la suministración del pentobarbital a cualquier persona, prescindiendo, id est, de la receta médica, aunque el demandante, al igual que la señora Pretty, solicite poder morir con dignidad y sin dolor. Esta interpretación, conjugando también lo dispuesto por el art. 2, garantiza que la normativa en cuestión respete la obligación de los Estados de proteger el derecho a la vida, ya que logra garantizar que la decisión de suicidarse a través de ayuda proceda de una libre voluntad del interesado y responda al objetivo legítimo de impedir los abusos del empleo de sustancias letales (se repite, por tanto, la tesis con pendientes resbaladizas). 
Por lo tanto, según el margen de apreciación de los Estados miembros sobre cuestiones internas, el Tribunal Europeo considera que no se ha violado el art. 8 del Convenio en la previsión normativa que supedita la entrega de la sustancia letal a una valoración psiquiátrica.

Que a la persona capaz de formar libremente su propio juicio y de actuar según el mismo se le reconozca el derecho de decidir el modo y el momento en que su vida debe terminar es uno de los aspectos del derecho al respeto de la vida privada conforme a lo establecido en el art. 8 del Convenio, que se reitera en la decisión Koch c. Alemania ${ }^{17}$, pero no en la ratio decidendi de la parte dispositiva.

En este caso, el demandante es Ulrich Koch, ciudadano alemán, cuya esposa - que a raíz de un accidente estaba casi totalmente paralizada y que se había visto obligada a un tratamiento de ventilación artificial y cuidados de enfermería continuos - había expresado conscientemente su deseo de morir, aunque era consciente, tras la evaluación médica, de una esperanza de vida de al menos quince años, y probablemente, ante esta perspectiva de largo sufrimiento e incapacidad, la voluntad de no querer vivir más se había hecho aún más fuerte. La señora Koch solicitó autorización al Federal Institute for Drugs and Medical Devices para obtener una dosis de pentobarbital sódico, pero sin éxito.

Dicha decisión de no conceder la autorización se basaba en el hecho que la posible concesión sería contraria a lo dispuesto en el German Narcotics Act, que establece que las sustancias enumeradas en ella (incluido el pentobarbital) no pueden ser entregadas si su finalidad no es el mismo mantenimiento en vida del solicitante (Maisto, 2011: 1 y ss.).

La esposa de Ulrich Koch se suicidó en Suiza, asistida por la organización Dignitas. El marido inició acciones judiciales para obtener el reconocimiento de la ilegalidad de la decisión del Instituto Federal Alemán por no haber concedido el medicamento con fines letales, pero tanto el Tribunal Administrativo como el Tribunal de Apelación declararon inadmisible el recurso, alegando que el demandante, en virtud del derecho nacional y del art. 8 del CEDH, no podía invocar derechos que no le corresponden, ya que no estaba legitimado a continuar un recurso presentado por su esposa fallecida: al demandante, id est, no se le concedió dicha capacidad jurídica. El Tribunal Constitucional ante el que se presentó el caso llegó a la misma conclusión, ya que el demandante no podía ejercer un derecho intransferible, como el derecho a la protección de la dignidad humana de su esposa fallecida.

El señor Koch, agotados todos los recursos internos, decidió recurrir al Tribunal Europeo, alegando que la inadmisibilidad de la demanda de su difunta esposa violaba el art. 8 del CEDH, en la medida en que la obligó a desplazarse a Suiza para cumplir con su voluntad, no reconociéndole, por consiguiente, el derecho a una muerte digna; el demandante también denunció la violación

17 Tribunal Europeo de Derechos Humanos, Sección 5a 19 de julio de 2012, caso Koch c. Alemania. Véanse Crivelli (2012: 1 y ss.); Parodi (2013a: 1 y ss.). 
del art. 13, porque las jurisdicciones internas (administrativa y constitucional), al negarle la posibilidad de que se le abordara la cuestión de fondo, violaban su derecho a un recurso efectivo.

El Tribunal Europeo, rechazando las solicitudes del Gobierno, que se constituyó en el proceso, admitió el recurso y se pronunció sobre la cuestión planteada. A diferencia de lo que se ha señalado anteriormente sobre el caso Sanles c. España ${ }^{18}$, los jueces de Estrasburgo reconocieron que el demandante es portador de derechos propios procedentes del art. 8 y eso a la luz de su larga relación matrimonial (25 años) con la señora fallecida y, sobre todo, la plena participación de la voluntad de su esposa de poner fin a su vida. Todo esto señala las diferencias con el caso Sanles y permite que el señor Koch sea considerado como un sujeto directamente afectado por el rechazo del Instituto Federal a no conceder el medicamento letal solicitado por su esposa.

Después de mencionar sus precedentes, regulados sobre los hechos concretos de los que habían surgido ${ }^{19}$, el Tribunal de Estrasburgo, entrando en el fondo del asunto, reconoció la violación del derecho exart. 8, dado que los jueces alemanes, al rechazar el examen de fondo de la solicitud del demandante para obtener la autorización y adquirir un medicamento letal, con la finalidad de permitirle un fin digno a la vida de su esposa gravemente enferma, y ya que antes de morir había emprendido la vía judicial para que se le reconociera ese derecho, integraban una violación a la protección de la vida privada. En conformidad con sus precedentes, entonces, el Tribunal Europeo declaró inadmisible la alegación relativa a la violación de los derechos de la esposa, teniendo en cuenta el carácter intrasmisible del derecho en cuestión.

Más allá de las afirmaciones de carácter procesal, lo que es importante subrayar es que el Tribunal Europeo decidió reafirmar, hasta con un obiter dictum, que al impedirle a una persona que elija por sí misma la interrupción de su existencia, ya no considerándola digna, no se puede excluir que se produzca una injerencia en el derecho garantizado por el mencionado art. 8 del CEDH.

La decisión del Tribunal Europeo, que es de carácter procesal, además de recordar el respeto del principio de subsidiariedad y del margen de apreciación, concluye afirmando que

[...] el mecanismo de protección previsto en el Convenio prevé funciones distintas para el Tribunal Europeo y los ordenamientos nacionales, exigiendo a estos que proporcionen una compensación por las violaciones de los derechos convencionales, y dejando al Tribunal el ejercicio de una función de supervisión conforme al principio de subsidiariedad. Este principio se hace aún más riguroso si la reivindicación se refiere a un asunto para el que el Estado tiene un margen de apreciación signifi-

18 En ese aspecto es diferente del caso Sanles, al cual se remite en el $₫ 43$.

19 La referencia a la concreción como método de análisis es imprescindible en el estudio de la materia que se está tratando, tal como pone de relieve Veronesi (2007: 5 ss.). 
cativo, como en los casos en que los Estados Miembros están lejos de alcanzar una posición unánime (Crivelli, 2013: 3; traducido por el autor).

\section{LAS NORMAS PARA LA SOLICITUD DE PRÁCTICA EUTANÁSICA DEBEN SER SIEMPRE CLARAS Y TRANSPARENTES}

La última decisión que merece ser mencionada — inherente al final de la vida según lo dispuesto por el art. 8 y (no solo) del art. 2- se focaliza sobre la legislación suiza que, en Europa, es sin duda una de las más liberales ${ }^{20}$.

Alda Gross era una anciana ciudadana suiza de 80 años. No padecía ninguna enfermedad, y mucho menos una enfermedad degenerativa incurable que la condujera a la muerte en poco tiempo. Ella, solamente, ya no lograba soportar su progresivo, aunque fisiológico, envejecimiento y la consiguiente pérdida de las propias capacidades psico-físicas, incluso su imparable deterioro: por dicha razón, la señora Gross decidió que quería poner fin a su vida ${ }^{21}$, ya que no la consideraba una vida digna. Intentó suicidarse y, sin lograrlo, siguió firme en su decisión solicitando la suministración de pentobarbital sódico, única sustancia que podía asegurarle la muerte sin el riesgo de un nuevo fracaso.

Como ya hemos examinado anteriormente, incluso en un ordenamiento permisivo como el suizo ${ }^{22}$, la suministración de sustancias clasificadas como letales no es totalmente libre, sino que está subordinada a algunas, específicas y necesarias, circunstancias, entre las cuales se halla la de la expedición de la receta médica, conforme a normas muy precisas. Las mismas, en este ordenamiento, no son establecidas por $1 \mathrm{ey}^{23}$, sino en las directrices de la Academia Suiza de Ciencias Médicas (ASSM), donde se indican las circunstancias y las condiciones que autorizan al personal médico a ayudar al suicidio mediante la prescripción del medicamento solo cuando el paciente se encuentre en una fase terminal de la enfermedad y cuando el sufrimiento que padece resulta ser intolerable. Además, para acceder a la prescripción del fármaco debe verificarse el requisito subjetivo, a través del cual el paciente debe expresar de manera libre la propia voluntad de poner fin a su existencia.

20 Tribunal Europeo de Derechos Humanos, Sección 2a, 14 de mayo de 2013, caso Gross $c$. Suiza. Véanse Parodi (2013b: 1 y ss.); Vigato (2013: 960-962).

21 Sobre el empleo del término enfermedad, pero con su acepción lingüística más débil, es decir, el de «estar mal», véase Ciervo (2013: 6).

22 La clasificación entre ordenamientos permisivos (legalizan, aunque sea parcialmente, la ayuda a morir) y no permisivos (imponen la prohibición absoluta de la ayuda a morir) es propuesta por Casonato (2012: 112).

23 Véase el art. 115 del código penal suizo. Cfr. al respecto también Di Carlo (2012: 627 y ss.); Ragone (2013: 665); Crivelli (2013: 4); Silva (2017: 312). 
Por lo tanto, el requisito patológico siempre debe ser acompañado por el requisito subjetivo, y viceversa: la falta de uno de los dos requisitos hace imposible la entrega del medicamento letal.

La falta de prescripción, dada la ausencia de uno de los dos factores antes mencionados, es la causa del inicio del procedimiento judicial iniciado por la demandante, que la llevará a interponer el recurso ante la Secretaría de los Jueces de Estrasburgo. De hecho, la señora Gross había consultado a varios médicos que, aun considerándola capaz de tomar la decisión con plenas facultades mentales, constataron que ella no sufría de ninguna enfermedad, tanto menos terminal, y por lo tanto se negaron a prescribir la sustancia. La autoridad judicial también rechazó la reclamación, confirmando la elección realizada por los médicos y no constatando ninguna vulneración del Convenio Europeo para la Protección de los Derechos Humanos, ya que la señora Gross presumía la violación de su derecho a elegir cómo y cuándo morir.

El incumplimiento de las normas del CEDH también fue argumentado por la Corte Suprema Federal, que consideró razonable la presencia de las reglas exigidas por la ASSM. La mujer recurrió al TEDH alegando también la violación del art. 8 .

Los precedentes de este caso son las sentencias Pretty y Haas, en las se declaró que la elección del solicitante de evitar lo que, a su juicio, es una vida dolorosa y sin dignidad, entra plenamente en el ámbito de aplicación del art. 8 del Convenio. Por otra parte, el segundo párrafo de este artículo se refiere a las restricciones que el Estado decida imponer. Sin embargo, estas restricciones no están previstas en la ley, sino más bien en las directrices elaboradas por una organización médica ${ }^{24}$.

Ahora bien, en las directrices suizas no se tiene en cuenta claramente, por lo menos en lo que se refiere al Tribunal Europeo, la situación concreta en la que se encontraba la demandante, en su condición de persona no moribunda, sino que deliberadamente desea suicidarse.

Esta falta de previsión ha causado a la señora Gross un estado de sufrimiento en el que no habría incurrido si la normativa hubiera sido más clara y comprensible $(\$ 65-66)$.

Con respecto a la violación del derecho garantizado a la demandante por el art. 8 del CEDH -aunque no entrando en el fondo del asunto y respetando el margen de apreciación-, el Tribunal Europeo no especifica si existe una obligación por parte de los Estados para que prescriban el fármaco letal a personas que, no padeciendo ninguna patología terminal, requieran el suicidio de manera consciente.

24 Las directrices son «recomendaciones desarrolladas de forma sistemática para ayudar a médicos y pacientes en la toma de decisiones sobre la gestión adecuada de condiciones clínicas específicas», según la fórmula acuñada por el Institute of Medicine (1992) citado en Plebani y Trenti (2002: 23). 
Por un lado, el margen de apreciación sirve al Tribunal Europeo para no pronunciarse sobre la existencia o inexistencia de una obligación por parte de los Estados para regular la practicas de eutanasia; por otro lado, en dicha cuestión los jueces parecen no tener en cuenta que se exige al Estado suizo un surplus de reglamentación en la materia ya disciplinada ${ }^{25}$.

Para señalar las incoherencias de esta última jurisprudencia, parece muy importante recordar el contenido de las opiniones disidentes adjuntas a la sentencia, entre las que destaca la del presidente del Tribunal Europeo, el juez Raimondi, redactada junto con los jueces Jočienè y Karazaş.

Los jueces discrepantes opinan que las condiciones exigidas por la legislación suiza para prescribir una sustancia letal — contrariamente a lo supuesto por la demandante - son claras. De hecho, las directrices son exhaustivas a la hora de diseñar un sistema basado en los elementos que hemos definido como subjetivo y objetivo-patológico, y la señora Gross claramente no pertenece a la categoría de personas que se encuentran en una situación de final de la vida.

Por lo tanto — siempre según los jueces discrepantes - no se trata de una situación de garantía ilusoria del derecho convencional, como supone siempre la demandante; Suiza, respetando el margen de apreciación que se le atribuye a la discrecionalidad legislativa estatal en dicha materia, no reconoce el derecho a solicitar la interrupción de la vida, salvo a las personas que se encuentren en una fase terminal e irreversible de la enfermedad que los obliga a sufrimientos insoportables, en la que no se incluye el caso Gross Por lo tanto, los jueces discrepantes excluyen la violación del art. 8 del CEDH (Crivelli, 2013: 5).

Volviendo a la cuestión procesal, pero con aspectos sustanciales, el Gobierno suizo apeló a la Gran Cámara, que declaró inadmisible el recurso de la señora Gross $^{26}$, por haber fallecido mientras tanto ${ }^{27}$ y condenó la mala conducta y el abuso por parte de su abogado, el cual había seguido con el proceso de apelación ante el CEDH, callando sobre el fallecimiento de su cliente (porque, paradójicamente, el mismo no fue informado).

El fallo de la Gran Sala deja sin efecto jurídico la decisión de la Sección II, que, como en el caso Haas, representaba una especie de apertura a la eutanasia por parte de la Convención, al reconocer un derecho individual a decidir cuándo y cómo debe finalizar la vida de una persona, y que ello constituía una de las implicaciones del respeto a la vida privada, siempre que el sujeto estuviera en

25 Como si la protección de la discrecionalidad legislativa, en ausencia de un compartido idem sentire en la materia que es objeto de análisis, pudiera reducirse si la decisión (sobre los hechos) se dirigiera únicamente al Estado que, contrariamente a los demás, produjo una amplia normativa que ya disciplina (permitiendo) la eutanasia.

26 Tribunal Europeo de Derechos Humanos, Gran Sala, Gross c. Suiza, del 30 de septiembre de 2014. Sobre decisión se remite a Razzano (2014: 65-67).

27 Después de un suicidio asistido tras recibir una receta de pentobarbital, que es una droga letal. 
condiciones de formar libremente su propio pensamiento y actuar en consecuencia.

\section{LA INTERRUPCIÓN DE LOS TRATAMIENTOS QUE SALVAN LA VIDA CUANDO DERIVAN DE UNA OBSTINACIÓN IRRAZONABLE}

Nos encontramos ahora ante otro caso que, aunque no entra en la vertiente de las prácticas de eutanasia ${ }^{28}$ —a diferencia de lo que sostienen los jueces que discrepan de la parte dispositiva de la decisión ${ }^{29}$ y de la cuidadosa doctrina (Razzano, 2015a: 169-184, y Santone, 2015: 6) — merece atención incluso solo por la delicadeza de la temática inherente a la legitimidad del rechazo de los tratamientos para salvar una vida (Casonato, 2015: 498), sobre la que el TEDH ya se había expresado en la ratio decidendi del caso Pretty.

El Tribunal Europeo, en el caso Lambert ${ }^{30}$, tuvo que decidir sobre las limitaciones del Estado para actuar ante una solicitud de interrupción de tratamientos que salvan la vida, como la nutrición y la alimentación artificiales. En el ordenamiento francés se ha procedido a la positivización del derecho a rechazar los tratamientos sanitarios, incluso los que salvan la vida (o sea, con la suministración simultánea de cuidados paliativos) — derecho de creación pretoria por parte de la Court de Cassation - en la denominada Ley Leonetti, es decir, en la Loi $n$. 2005-370 du 22 avril 2005 relative aux droits des malades et a la fin de vie (actualizada el 27 de enero de 2016) con la que se modificó el Code de la santé publique.

28 En la medida en que no se trata de una petición de eutanasia directa activa, sino de un caso particular — como se tendrá ocasión de subrayar — de ensañamiento terapéutico.

29 Hajiyev, Šikuta, Tsotsoria, De Gaetano y Gritco, en particular en el punto 9. Por su «fuerza» se decide citar el punto 11 de la opinión conjunta: «[e]n 2010, pour célébrer son 50e anniversaire, la Cour a accepté le titre de Conscience de l'Europe en publiant un ouvrage ainsi intitulé. À supposer, aux fins du débat, qu’une institution, par opposition aux personnes composant cette institution, puisse avoir une conscience, pareille conscience doit non seulement être bien informée mais doit également se fonder sur de hautes valeurs morales ou éthiques. Ces valeurs devraient toujours être le phare qui nous guide, quelle que soit "l'ivraie juridique" pouvant être produite au cours du processus d'analyse d'une affaire. Il ne suffit pas de reconnaitre, comme la Cour le fait au paragraphe 181 de l'arrêt, qu'une affaire "touche à des questions médicales, juridiques et éthiques de la plus grande complexité"; il est de l'essence même d'une conscience, fondée sur la recta ratio, de permettre que les questions éthiques façonnent et guident le raisonnement juridique jusqu’à sa conclusion finale. C'est précisément cela, avoir une conscience. Nous regrettons que la Cour, avec cet arrêt, ait perdu le droit de porter le titre ci-dessus».

30 Una presentación exhaustiva del caso, acompañada por una nota crítica — que no compartimos porque el caso no se refiere a la eutanasia y porque es aceptable la afirmación según la cual, en el caso concreto, se está ante una vida artificial (vida biológica frente a vida biográfica)—, se encuentra en Razzano (2105b: 1 y ss.). Véanse, también, Zagrebelsky (2015: 1); Rivera (2015: 1 y ss.); Hennette-Vauchez (2015: 151-155); Ciervo (2017: 1 y ss.); Zambrano (2016: 1 y ss.). 
Además, es oportuno recordar que en Francia se reconoce la posibilidad de redactar las directives anticipées por parte de personas mayores de edad y que, prescindiendo de las eventuales indicaciones del paciente, el médico debe abstenerse de practicar tratamientos que resulten inútiles, desproporcionados o que no den resultados si no para mantener en vida de manera artificial; dichos actos, producto de una «obstination déraisonnable», pueden no ser iniciados o ser suspendidos.

Tras la entrada en vigor del art. 1 de la loi Leonetti, estos tratamientos:

ne doivent pas être poursuivis par une obstination déraisonnable. Lorsqu'ils apparaissent inutiles, disproportionnés ou n'ayant d'autre effet que le seul maintien artificiel de la vie, ils peuvent être suspendus ou ne pas être entrepris. Dans ce cas, le médecin sauvegarde la dignité du mourant et assure la qualité de sa vie en dispensant les soins visés a l'article L.1110-1031.

Si, por una parte, existe un amplio reconocimiento del derecho a rechazar los tratamientos, por otra, al igual que en la mayoría de los países europeos, también en Francia, el Código Penal sanciona el asesinato del consintiente y la ayuda al suicidio (art. 223-13).

Tras un accidente de coche, Vincent Lambert, que no ha dejado ningún testamento vital, se encontraba en un estado vegetativo desde el 2008. El 10 de abril de 2013, los médicos decidieron interrumpir la alimentación y disminuir la hidratación artificial, ya que ambas se consideraban expresión de los tratamientos definidos por la ley Leonetti como obstination déraisonnable. La decisión de los médicos fue apoyada por su esposa, la cual aseguraba que el marido le había expresado su deseo de morir en el caso de incapacidad; pero sus padres y hermanos impugnaron dicha decisión para que se restableciera la alimentación y se incrementara la hidratación (se trata, por ley, de una "procédure [médica] collégiale» que está estrictamente "formalizada»).

La vía judicial llevó hasta el Conseil d’État — que reformó la aplicación de la sentencia dictada por el Tribunal administrativo de Châlons-en-Champagne que había suspendido la decisión médica de interrumpir la nutrición artificialconsiderando legítima el 24 de junio de 2014 la elección de los médicos de interrumpir los tratamientos que mantenían en vida a Vincent Lambert.

Los padres y hermanos de Lambert, en ese momento, recurrieron al TEDH, que aceptó la solicitud de suspender la ejecución de la sentencia del Consejo de Estado y la prohibición de trasladar al paciente a otro hospital o al extranjero ${ }^{32}$. El 5 de junio de 2015, el Tribunal Europeo de Justicia entró en el fondo del asunto y dictó su sentencia.

La Gran Sala — con esta última decisión y en relación con el art. 2 CEDH—, en primer lugar, reconoció que no existe consenso entre los Estados miembros en

31 Así dicta el art. 1 de la L.1110-5 du code de la santé publique.

32 Tribunal Europeo de Derechos Humanos, Gran Sala, 5 de junio de 2015, caso Lambert y otros c. Francia, n. 46043/14. 
cuanto a la interrupción de los tratamientos que salvan la vida, incluso cuando los mismos constituyen ensañamiento terapéutico; en segundo lugar, reconoció que subsiste una idea común con respecto a la relevancia que deben tener los deseos del paciente a la hora de tomar decisiones. En estas circunstancias, el Tribunal Europeo considera que

[...] au début de la vie, il y a lieu d'accorder une marge d'appréciation aux États, non seulement cuanto sea la posibilidad de consentirre ou pas l'arrêt d'traitement maintenant artificiellement la vie et a ses modalités de mise en oeuvre, mais aussi quanto la façon de ménager un équilibre entre la protection du droit a la vie du patient et celle du droit au respect de sa vie privée et de son autonomie personnelle (\$148).

Además, el Tribunal Europeo es:

[...] pleinement consciente de l'importance des problèmes soulevés par la présente affaire, qui touche a des questions médicales, juridiques et éthiques de la plus grande complexité. Dans les circonstances de l'espèce, la Cour rappelle que c'est en premier lieu aux autorités internes qu'il appartenait de vérifier la conformité de la décision d'arrêt des traitements au droit interne et a la Convention, ainsi que d'établir les souhaits du patient conformément a la loi nationale. Le rôle de la Cour a consisté a examiner le respect par l'État de ses obligations positives découlant de l'article 2 de la Convention (\$181).

Entonces, el juez europeo —basándose también en las observaciones generales de las más altas autoridades médicas y éticas francesas- consideró que tanto la legislación francesa, según la interpretación del Conseil d’État, como el proceso que llevó a la decisión de interrumpir el tratamiento para salvar la vida deben considerarse compatibles con el art. 2 del Convenio.

Precisamente porque se trata de una hipótesis de ensañamiento terapéutico, la decisión ha sido remitida a un órgano médico colegiado, que está legitimado (sobre la base de pruebas científicas) para tomar una decisión «sin» el consentimiento del paciente; esto se considera posible precisamente porque no había un informe terapéutico con objeto de una "propuesta» de tratamiento ni siquiera minimamente eficaz.

Consciente de que se enfrentaba a un problema sin precedentes, el Tribunal reconoció el margen de apreciación y declaró que el motivo de apelación basado en el art. 8 de la Convención (derecho al respeto de la vida privada y familiar) era absorbido.

Finalmente, para el Tribunal Europeo, el médico puede intervenir desde la sencilla suministración de tratamientos paliativos hasta la sedación profunda y continua, o también hasta la interrupción de la alimentación y de la hidratación artificiales, si es para garantizar la interrupción del tratamiento en situaciones en las que el paciente esté inconsciente; esta disposición legislativa no comporta que el Estado francés incumpla sus obligaciones institucionales procedentes de la firma del Convenio. 


\section{CONCLUSIONES}

Otra decisión digna de mención, antes de hacer un balance sobre la jurisprudencia del TEDH en materia del final de la vida, es una sentencia que por varios aspectos recuerda la de Vincent Lambert, pero que por muchos otros se aleja, ya que ahora se trata de un caso de suspensión de la ventilación artificial en un recién nacido durante sus primeros días de vida.

Charlie Gard era un niño londinense de solo 10 meses al que se le diagnosticó un síndrome de depleción de ADN mitocondrial. Se trata de una enfermedad muy rara (de la que existen distintas formas), en la que la literatura médica - procedente de varias fuentes - habla de una casuística de solo 16 niños en todo el mundo. Frente a este síndrome genético-degenerativo no existe (hasta la fecha) un tratamiento científicamente válido.

La enfermedad mitocondrial que padecía Charlie afectó al cerebro, a los músculos y a las vías respiratorias, pero también al corazón, al hígado y a los riñones. El pequeño paciente también sufría de sordera y era incapaz de alimentarse y de respirar sin la ayuda de máquinas.

El pasado 27 de junio, el Tribunal de Estrasburgo (Poli, 2017: 752 y ss.) declaró inadmisible el recurso interpuesto por los padres de Charlie Gard contra las resoluciones de los tribunales internos ${ }^{33}$ que - siguiendo las indicaciones de los médicos que se ocupaban del niño- autorizaron la interrupción de los tratamientos de apoyo vital y comenzaron el de sedación paliativa.

Por consiguiente, los padres presentaron un recurso al TEDH denunciando la violación de los arts. 2 (derecho a la vida), 5 (derecho a la libertad y a la seguridad), 6 (derecho a un proceso equitativo) y 8 (derecho al respeto a la vida privada y familiar) del CEDH por parte del Reino Unido respecto al menor (los dos primeros artículos) y a ellos mismos (los dos últimos).

Para los demandantes, la interrupción de los tratamientos de apoyo vital constituyó una violación de las obligaciones positivas del Estado para la protección del derecho a la vida y de la libertad de las personas; además, el Tribunal de Apelación habría interferido de manera desproporcionada con sus decisiones sobre el derecho de los padres a respetar su vida privada y familiar.

El Tribunal Europeo consideró que el recurso era infundado e inadmisible. Específicamente, sobre la supuesta violación del art. 2 del CEDH, el Tribunal Europeo declaró - y remarcó - que las obligaciones positivas a las que el Estado debe responder en caso de protección del derecho a la vida no pueden interpretarse de manera tal que comprendan también el deber de garantizar tratamientos inapropiados — que no resulten validados por la comunidad científica- cuyos resultados se encuentren todavía en la fase de su primera experimentación.

33 Family Division of the High Court del 24 de febrero de 2017, confirmada por la Court of Appeal del 23 de mayo. Sucesivamente, también UK Supreme Court del 23 de mayo de 2017. 
A raíz de la imposibilidad de que el paciente recibiera medicamentos para mejorar la calidad de su vida, los tratamientos resultaban innecesarios y desproporcionados, constituyéndose como un ensañamiento terapéutico, fruto de una obstinación irrazonable. De ahí derivaba la autorización y la decisión de los médicos a que se interrumpiera cualquier medida de apoyo vital y la de los magistrados a validarlo.

Nos encontramos, una vez más, ante un caso en el que la opción terapéutica (rechazo de un tratamiento que salva la vida) no fue solicitada por un paciente en estado de conciencia, pero tampoco por una persona que decidía «de un día para el otro" mediante la redacción de un documento especial para hacer valer sus propias determinaciones en caso de que no hubiera tenido la posibilidad de elegir por sí mismo (porque era imposible). Estamos, en cambio, ante un sujeto que nunca ha podido expresar su voluntad.

El juez europeo, basándose en los precedentes recientes (casos Lambert y Glass.) y citando los principios que en él se enuncian, juzga el marco británico (normativo y aplicativo) compatible y adecuado al nivel de protección que el art. 2 del Convenio exige a los Estados suscriptores del Pacto Internacional. Sin embargo, el caso que nos ocupa presenta una particularidad: el paciente es menor de edad (tiene solo diez meses). Para los jueces europeos (por unanimidad), la voluntad del recién nacido $\mathrm{y}$, por consiguiente, la protección de su posición jurídica, se garantizaron gracias a la representación del tutor ante los tribunales británicos, que, designado a tal efecto, estableció una alianza terapéutica con el equipo médico, el cual tomó la decisión de proteger sus intereses con la mejor capacidad posible. De esa manera, se garantizó la disciplina del exart. 2 del $\mathrm{CEDH}$.

La particularidad del caso (dado que de un caso se trata, precisamente) revela, en primer lugar, que no se trata de una persona mayor de edad. Infundada también la parte del recurso que parametrizaba el art. 8 del CEDH en relación con los mismos demandantes, por haber los jueces londinenses interferido indebidamente con su patria potestad:

[...] examining the decisions taken by the domestic courts [...], the Court recalls that they were meticulous and thorough; ensured that all those concerned were represented throughout; heard extensive and high-quality expert evidence; accorded weight to all the arguments raised; and were reviewed at three levels of jurisdiction with clear and extensive reasoning giving relevant and sufficient support for their conclusions at all three levels. Accordingly, the Court does not see any element suggesting that those decisions could amount to an arbitrary or disproportionate interference ${ }^{34}$.

34 Tribunal Europeo de Derechos Humanos, Sección 1a, 27 de junio de 2017, caso Charles Gard y otros c. Reino Unido, $\$ 124$. Más reciente, véase también, por afinidad, el caso Afiri et Biddarri c. France, del pasado 25 de enero de 2018. 
Por consiguiente, se rechazó el recurso.

El Tribunal, después de las tres decisiones de órganos jurisdiccionales nacionales, dio inicio a la evaluación médica basada en parámetros (científicos), distintos del de los (amorosos) miembros de la familia, evaluando en los términos siguientes la situación clínica del pequeño paciente tratado en uno de los hospitales pediátricos más prestigiosos del mundo (el Great Ormond Street Hospital de Londres): no pudiendo pronosticar ninguna mejora posible, ni ventaja alguna con los tratamientos disponibles actualmente, y con la convicción (científica) de que el dolor aumentaría o no se restablecería de ninguna manera, los médicos estimaron que el interés del niño era rechazar los tratamientos (y por lo tanto morir) en lugar de seguir sufriendo (prolongando artificialmente la actividad vital). Esta decisión médica (en alianza terapéutica con el tutor) fue avalada por los jueces nacionales y por el Tribunal Europeo de Derechos Humanos.

Las autoridades judiciales elaboraron una jurisprudencia basada en el respeto de la autonomía del paciente, de la no malevolencia y de la beneficencia, es decir, en conformidad con los principios de no perjudicar y de actuar según el interés del paciente que se evalúa cuando, mediante un análisis comparativo, los beneficios no superen el sufrimiento físico y moral. En estos casos, el tratamiento sanitario no tiene más razón de ser actuado, salvo por ensañamiento terapéutico.

La pregunta fundamental es la siguiente: en este caso concreto, ¿quién tiene la última palabra sobre el tratamiento que se debe garantizar o suspender? ¿Los padres, los médicos o los jueces? Como veremos, la elección ha sido motivada tanto por la situación como por la patología. La elección no se planteaba entre dos perspectivas, es decir, entre la vida y la muerte, sino sobre cuál debía ser la mejor opción para el paciente: suspender los tratamientos, seguir con ellos o modificarlos.

Incapaz de decidir sobre sí mismo y por sí mismo según el principio del consentimiento informado; no tratándose siquiera de una persona que pudiera decidir previamente sobre sí mismo y por sí mismo gracias al instituto del testamento vital, ya que no solo se trata de un menor, sino de un paciente que nunca tuvo la oportunidad de desarrollar su propia conciencia.

La particularidad del caso — parecido al de Vincent Lambert- está representada por la situación en la que se encuentran las partes ampliadas con la alianza terapéutica (familiares, tutores y médicos), que se encuentran en posiciones diametralmente opuestas.

Para trazar con mayor eficacia el marco, que llevará a inclinarse positivamente sobre la decisión adoptada sucesivamente por los jueces, es menester recordar que la enfermedad no se podía curar con ninguna terapia validada científicamente. Los tratamientos propuestos por otros centros de asistencia sanitaria (que actúan fuera del Reino Unido) ni siquiera han alcanzado la fase 
de investigación preclínica, ya que, por ejemplo, no se han realizado estudios empíricos para evaluar su toxicidad ${ }^{35}$.

Por lo que respecta al síndrome en cuestión, el posible efecto farmacológico positivo sobre el ser humano no alcanza ni siquiera la fase de la posibilidad. Ante este hecho, la decisión de los médicos, primero, y de los jueces, después, es más que comprensible.

Las decisiones de dichos sujetos institucionales fueron tomadas de manera muy correcta (veracidad, conveniencia u oportunidades demostradas), en la medida en que las resoluciones judiciales se presentaron después de haber adquirido una pluralidad de opiniones expresadas por personalidades muy acreditadas pertenecientes al mundo médico-científico ${ }^{36}$ que declararon que el pequeño paciente estaba viviendo con sufrimientos crecientes no medicables.

Cuando por una enfermedad de mal pronóstico el tratamiento resulta inútil y desproporcionado, no se puede sino rendirse ante ella, con la conciencia de que todo se ha hecho y que nada más puede hacerse. El dilema que se le planteó a la magistratura es si es justo someter a un recién nacido (o a cualquier otra persona) a terapias "extraordinarias" (es decir, aún no experimentadas) sobre el principio (no escrito y no «extraíble» de ninguna norma jurídica) que en caso de riesgo de vida se puede (se debe) hacer todo lo posible: «sobre todo cuando el precio de sufrimiento del "es mejor probar de todo" lo paga un ser indefenso, que nada puede decir sobre sí» (Zuffa y Toraldo di Francia, 2017: 1 y ss.).

Por lo tanto, no hay un favor mortis contra un favor vitae (Villone, 2017: 1 y ss.), sino la búsqueda del mejor interés para el niño.

Aunque el desarrollo médico-científico parezca fecundo, la decisión que se debe tomar es aqui y ahora; la respuesta debe darse cuando es solicitada y puede ser adoptada (también) por los jueces que pueden tener derecho a la última palabra. Esto puede ocurrir cuando una decisión de la alianza no se adopta en la relación que se establece entre los miembros de la familia ${ }^{37}$ y los médicos, precisamente debido a una evaluación diferente y divergente del best interest of child; sin embargo, la decisión hay que tomarla y hay que hacerlo dirigiéndose a la autoridad judicial, cuyas evaluaciones e indicaciones (también esto se ha visto) son siempre apelables, hasta el TEDH.

35 De hecho, según las directrices sobre el fármaco, los estudios en una primera fase se realizan «in vitro» con el fin de comprender las características de la molécula química de la que se cree que puede extraerse un medicamento a través de una serie de pruebas practicadas en el laboratorio; solo cuando se determine que la molécula tiene efectos terapéuticos potenciales, la fase siguiente será la de la experimentación mediante estudios con animales vivos. Esto significa que, en el caso en cuestión, no solo no podía asegurarse la eficacia del medicamento, sino tampoco de su falta de toxicidad.

36 Recordadas en los $\$ \$ 6$ y ss. en el punto A en Tribunal Europeo de Derechos Humanos, Sección 1ª, 27 de junio de 2017, caso Charles Gard y otros c. Reino Unido.

37 Critica la decisión de inadmisibilidad y, para darle mayor peso, argumenta que se debe reconocer la potestad paternal Schettino (2017: 7 y ss.); Venturi (2017: 1 y ss.). 
En la misma línea jurisprudencial, más recientemente, es el caso Alfie Evans (AA. VV., 2018: 1-76; Adamo, 2018a: 2). Después de su nacimiento (mayo de 2016), al niño le fueron diagnosticadas una serie de enfermedades neurológicas, que pronto se extendieron desde problemas de la vista hasta un retraso global en el desarrollo cognitivo; hasta que, después de una grave neumonía, entró en coma irreversible. En ese momento se diagnósticó una neuropatología degenerativa. La situación, extremadamente crítica, no tenía solución con los instrumentos y las terapias disponibles en ese momento por la práctica médica y ni siquiera por estudios e investigaciones científicas en dicho campo. Entonces, los médicos que curaban al niño pensaron, en ciencia y conciencia, que seguir manteniéndolo vivo, suministrándole una ventilación artificial, no correspondía a su mejor interés. Por lo tanto, el equipo de médicos solicitó al órgano jurisdiccional competente la interrupción del tratamiento —considerándolo inapropiado y totalmente ineficaz, inútil y, sobre todo, expresión de una obstinación irrazonable--, dejando que la enfermedad se desarrollara de forma natural.

Ante este marco, tampoco era una cuestión de optar a favor de la vida o a favor de la muerte, sino de poner de manifiesto que no se estaba ante una diferente visión cultural (por la vida o por la muerte, precisamente), sino más bien ante diferentes interpretaciones de un mismo punto, es decir, sobre cuál debía ser el «mejor interés» del pequeño Alfie. Considerada la situación del caso concreto, la cuestión determinante era quién debía tener la última palabra sobre el tratamiento (si debía garantizarse o suspenderse).

Como veremos, la elección se debió tanto a la situación de contraste como a la patología del pequeño Alfie. Si los médicos del Alder Hey Children's estimaban que el sufrimiento que padecía el niño ya no era aceptable dada la situación clínica irremediablemente comprometida, por su parte, los padres estaban convencidos de que el mejor interés de su hijo no era el de «morir».

En un sistema bien reglamentado, como el del derecho británico, ante una contraposición concreta sobre cuál fuera el «mejor interés» del pequeño paciente, recurrir al juez era prácticamente obligatorio. Aun recordando la decisión del caso Charlie Gard, los jueces ingleses establecieron que la condición clínica del pequeño Alfie era irreversible, que le causaba sufrimientos innecesarios y, por tanto, inaceptables, y constatando además que el cerebro estaba totalmente comprometido (por la total destrucción de la materia blanca y la gris largamente comprometida), que ningún tratamiento, ni siquiera experimental, habría podido ser eficaz en invertir o detener la evolución de la enfermedad. Según los médicos que lo curaban, el pequeño Alfie se mantenía en vida con un respirador artificial, ya que no hubiera podido respirar de manera autónoma. Por lo tanto, la decisión fue interrumpir el tratamiento iniciando los cuidados paliativos, los únicos que se consideraron capaces de ofrecer un acompañamiento digno en la última fase de su corta existencia. Además de determinarse así, el juez británico asumió que el traslado a un hospital italiano obligaría al pequeño Alfie a una mera prolongación del sufrimiento, que, de hecho, podría haber aumentado (debido a la alta predisposición a contraer infecciones) tanto que llevó al mismo juez a sostener 
que «nadie querría que Alfie muriera durante el viaje». En la certeza concreta de que no existía ninguna terapia (ni siquiera en Italia) capaz de detener el curso infausto de la enfermedad, el viaje para el ingreso en un hospital italiano no fue autorizado. De ese modo, el juez daba curso a la evaluación médica basada en parámetros (científicos) distintos de los (emocionales) de los miembros de la familia, asumiendo en los términos que siguen la situación clínica del pequeño paciente. Dado que no era posible pronosticar ninguna mejora posible ni ventajas de ningún tipo con las terapias disponibles, el hecho de tener conciencia (científica) de que el dolor podría haber aumentado o no haber disminuido de ninguna manera, llevó a los médicos a considerar que el interés del pequeño Alfie era interrumpir el tratamiento (y por lo tanto llevarlo a la muerte), en lugar de seguir sufriendo (prolongando la actividad vital de manera artificial).

A la luz de la jurisprudencia del Tribunal Europeo - para extrapolar las máximas aplicables erga omnes - pueden señalarse varias observaciones.

Empezamos por señalar que la jurisprudencia europea siempre logra establecer claras diferencias prácticas, sin confundir nunca (porque los considera objetivamente distintos) el rechazo de los tratamientos (incluso el de salvar la vida) con la eutanasia y, en esta, la ayuda al suicidio con el asesinato del consintiente. El rechazo del ensañamiento terapéutico representa otra situación que pone en el plato de la balanza el mejor interés del paciente, presentando un peso mayor no solo en las decisiones médicas, sino también las de los familiares.

Por lo tanto, la jurisprudencia del TEDH legitima el vínculo a la solicitud de ayuda a la muerte, es más, lo exige para respetar el art. 2 del CEDH, dejando, en todo caso, a la apreciación de los Estados, la decisión de sancionar penalmente el asesinato del consintiente y la ayuda al suicidio, es decir, el de legalizarla. En cambio, el suicidio asistido no halla protección en el art. 2 del CEDH dado que, protegiendo el derecho a la vida, no puede proteger lo contrario, lo que para el Tribunal Europeo es el derecho a la muerte.

El margen interpretativo que ofrece la disposición del mencionado art. 8 (derecho a la vida privada) ha sido objeto de una interpretación extensiva susceptible de diversas reivindicaciones de protección de situaciones jurídicas para el reconocimiento del derecho a decidir cómo y cuándo poner término a la propia vida; el Tribunal también subrayó la necesidad de procedimientos y condiciones restrictivas para la legitimidad del suicidio asistido ${ }^{38}$.

Por otra parte, el Tribunal no ha establecido todavía si los Estados tienen la obligación de responder positivamente a las demandas de los ciudadanos que solicitan la autorización para poner fin a su existencia, al contrario, si se observa con atención refiriéndose al derecho de una persona a decidir cómo y en qué momento poner fin a su vida, siempre que dicha voluntad y el acto consiguiente sean absolutamente libres, solo ha tenido (hasta ahora) un alcance «retórico» $\mathrm{y}$ «no

$\overline{38 \text { Caso Hass. c. Suiza, }} \S 51$. 
concreto» (aunque no sea menos importante), y el Tribunal nunca ha condenado a ningún Estado por no haber reconocido el «derecho a morir dignamente».

El TEDH (hasta la fecha) reconoce un amplio margen de apreciación si se deben legalizar o no las prácticas eutanásicas, pero no sobre cómo hacerlo. Si se decide sobre la reglamentación de las prácticas eutanásicas, el margen de apreciación se retrae y el juez europeo se considera competente para examinar el fondo del recurso y para dictar sentencias particularmente incisivas.

Estas conclusiones son potencialmente variables si se presta especial atención a la ratio decidendi que subyace en la parte dispositiva de todas las decisiones y al uso que puede hacerse de la prueba de proporcionalidad.

Una simple constatación es que - en los ordenamientos no permisivos-el único caso al que hay que referirse es el caso Pretty, ya que en todos los demás la cuestión remite a un ordenamiento en el que se legaliza (al menos) la ayuda al suicidio.

Desde Pretty en adelante, el TEDH ha reconocido claramente que el derecho a poner fin a la propia vida se inscribe en el ámbito del derecho fundamental del respeto de la vida privada (art. 8), protegido por la Convención. Por otra parte, el reconocimiento de un derecho implica una obligación positiva para el Estado contrayente con el fin de garantizar su reconocimiento y, por tanto, su protección (Tega, 2012: 184).

Cabe preguntarse entonces si los ordenamientos no permisivos y/o aquellos que permiten la ayuda médica a la muerte ${ }^{39}$, pero con límites excesivamente estrictos $^{40}$, pueden superar con seguridad el posible control del Tribunal Europeo en caso de que se le someta el asunto. La respuesta no parece ser obvia.

De hecho, el Tribunal Europeo "ha salvado» la legislación británica, entre otras cosas porque ha superado la prueba de proporcionalidad. Esta legislación, que perseguía un objetivo legítimo, utilizaba una correcta proporcionalidad entre los medios empleados y el objetivo que se debía alcanzar (la protección del derecho a la vida de los pacientes y su autonomía personal).

La Ley del Suicidio (Suicide Act) de 1961 despenalizó el suicidio tanto en Inglaterra como en Gales; el art. $2 \$ 1$ de dicha legislación establece que: « $[\mathrm{t}]$ oda persona que facilite, aliente, recomiende $\mathrm{u}$ organice el suicidio o una tentativa de suicidio de un tercero será sometida, tras su acusación, a una pena máxima de reclusión de catorce años». Además, no existe la obligación del recurso

39 Se emplea la expresión con el mismo alcance semántico que la utilizan en AA. VV. (2019: 1 y ss.) y, por lo tanto, en relación con la ayuda al suicidio y al asesinato del consintiente.

40 Corte const., sent. n. 242/2019. Según el Tribunal Constitucional italiano, la ayuda al suicidio solo puede ser solicitada por una persona "(a) affetta da una patologia irreversibile e (b) fonte di sofferenze fisiche o psicologiche, che trova assolutamente intollerabili, la quale sia (c) tenuta in vita a mezzo di trattamenti di sostegno vitale, ma resti (d) capace di prendere decisioni libere e consapevoli», la referencia a la presencia de tratamientos de soporte vital aparece como límite excesivamente restrictivo, si no del todo irrazonable (Adamo, 2020: 37-47). 
penal, dado que el art. $2 \$ 4$ dispone: «[n]o se emprenderán diligencias por un delito al presente artículo, salvo por el "Director of Public Prosecutions" o con su aprobación». A partir de ello (Zagrebelsky, 2017: 3-5; contra, al menos, Zanichelli, 2011: 411), se llevó a cabo la prueba de proporcionalidad ${ }^{41}$, según la cual las limitaciones de los derechos reconocidos por el Convenio deben orientarse a uno de los fines previstos en el art. $8 \$ 2$, es decir, "para la seguridad nacional, la seguridad pública, el bienestar económico del país, la defensa del orden y la prevención del delito, la protección de la salud o de la moral, o la protección de los derechos y las libertades de los demás».

También se debe a la elasticidad de la norma penal inglesa que haya sido posible que se adecuara al parámetro convencional «dúctil»: falta de nivel edictal mínimo, no obligatoriedad de la acción penal (Zagrebelsky, 2016: 254; Ciervo, 2011: 3).

Desde hace veinte años (y a partir del caso Pretty) se ha asistido a una jurisprudencia convencional que ha consagrado el derecho de poner fin a la vida ${ }^{42}$ en el ámbito del derecho fundamental al respeto de la vida privada del art. $8^{43}$. El límite absoluto de la ayuda al suicidio ante una expresión de consentimiento genuino e informado (en una palabra, libre) no parece servir para alcanzar ninguno de los objetivos antes mencionados, cuya presencia solo puede legitimar la restricción de un derecho convencional.

También es interesante observar que, en el $\$ 74$ de la sentencia Pretty, se cita la decisión del caso Rodríguez, presentada por el Tribunal canadiense, que sostenía la legitimidad de la prohibición absoluta de ayuda al suicidio. Pero, precisamente el Tribunal Supremo canadiense ahora ha cambiado radicalmente su jurisprudencia

41 La posibilidad de «un régimen de aplicación y de apreciación por parte de la justicia que permite tener en cuenta en cada caso concreto tanto el interés público en instruir diligencias como las exigencias justas y adecuadas de la retribución y la disuasión» (\$76), por lo tanto, no ha hecho desproporcionada la norma de prohibición del suicidio asistido. Se repite: el derecho «d'un individu de décider de quelle manière et à quel moment sa vie doit prendre fin, à condition qu'il soit en mesure de former librement sa volonté à ce propos et d'agir en conséquence», así el Tribunal Europeo de Derechos Humanos, Sección $1^{a}$, 28 de 2011, caso Haas c. Svizzera, $\$ 51$. En tal pasaje, y con referencia al caso Pretty, se remite explícitamente a Koch c. Germania, \$\$ 51-52: «la Cour a déclaré ne pouvoir exclure que le fait d'empêcher par la loi la requérante d'exercer son choix d'éviter ce qui, à ses yeux, constituera une fin de vie indigne et pénible représente une atteinte au droit de l'intéressée au respect de sa vie privée, au sens de l'article $8 \$ 1$ de la Convention. Dans l'affaire Haas c. Suisse, la Cour a encore précisé cette ligne de jurisprudence en reconnaissant que le droit d'un individu de décider de quelle manière et à quel moment sa vie doit prendre fin, à condition qu'il soit en mesure de former librement sa volonté à ce propos et d'agir en conséquence, était l'un des aspects du droit au respect de sa vie privée au sens de l'article 8 de la Convention".

43 Sobre la interpretación evolutiva (también) de los derechos constitucionales nacionales y sobre la (necesaria) modificación de la legislación interna a la luz del CEDH de la jurisprudencia correspondiente, véase, por lo menos, Cartabia (2011: 636 y ss.). 
y ha declarado inconstitucional la prohibición absoluta de solicitud al suicidio asistido ${ }^{44}$. Por lo tanto, con escasa probabilidad el TEDH podrá reiterar la discutible motivación de que es difícil determinar en concreto las diferentes situaciones de personas con una enfermedad terminal y malograr el riesgo de abusos que podrían derivar de la introducción de una «flexibilidad» (siempre $\$ 74$ ) a la prohibición general de suicidio asistido ${ }^{45}$.

\section{Bibliografía}

Adamo, U. (2018a). Cultura della vita e cultura della morte: interrogativi sul caso del piccolo Alfie Evans. LaCostituzione.info, 1-5-2018. Disponible en: https:// bit.ly/3mgsI0R.

- (2018b). Costituzione e fine vita. Disposizioni anticipate di trattamento ed eutanasia. Milan: Cedam.

- (2020). La Corte costituzionale apre (ma non troppo) al suicidio medicalmente assistito mediante una inedita doppia pronuncia. BioLaw Journal - Rivista di BioDiritto, 20(1), 27-64.

Bestagno, F. (2012). Art. 2. Diritto alla vita. En V. Zagrebelsky, P. De Sena y S. Bartole (eds.). Commentario breve alla Convenzione europea per la salvaguardia dei diritti dell'uomo e delle libertà fondamentali (pp. 36-63). Padova: Cedam.

Bifulco, R. (2003). Esiste un diritto al suicidio assistito nella CEDU? Quaderni costituzionali, 23(1), 166-167.

Butturini, D. (2011). Note a margine di Corte EDU. Haas contro Svizzera. Rivista AIC, 3 .

Canestrari, S. y Faenza, F. (2008). Il principio di ragionevolezza nella regolamentazione biogiuridica: la prospettiva del diritto penale. Criminalia, 1.

Cartabia, M. (2011). In tema di «nuovi» diritti. En VV. AA. Scritti in onore di Franco Modugno, Tomo I. Napoli: Jovene.

Casonato, C. (2012). Introduzione al biodiritto. Torino: Giappichelli.

- (2015). Un diritto difficile. Il caso Lambert fra necessità e rischi. La nuova giurisprudenza civile commentata, 9, 489-501.

$\overline{44}$ Nos referimos a la reciente decisión del Tribunal Supremo de Canadá (caso Carter c. Canadá, del 6 de febrero de 2015), que, gracias también a una modulación en el tiempo de los efectos de su decisión, declaró la inconstitucionalidad de la prohibición penal (art. 241. b c. p.) que prohíbe de manera absoluta y, por tanto, injuzgada para el Tribunal, la ayuda al suicidio, así como la eutanasia activa. La ayuda médica a la muerte, aunque se trate de determinadas condiciones, constituye un verdadero derecho fundamental de la persona. Sobre el tema, Adamo (2018b: 183).

45 Tega (2012: 115): «[i]l margine può essere "neutralizzato" [...] attraverso l'uso del generale canone della proporzionalità, cioè il vaglio che la Corte fa della "necessarietà" della limitazione statale del diritto in questione rispetto ad una società democratica». 
- (2020). La giurisprudenza costituzionale sull'aiuto al suicidio nel prisma del biodiritto, fra conferme e novità. En C. Padula (ed.). Una nuova stagione creativa della Corte costituzionale? Napoli: Editoriale Scientifica.

Ciervo, A. (2011). L'insostenibile leggerezza del margine di apprezzamento. Il problema dell'eutanasia davanti ai giudici di Strasburgo: in margine al caso Haas c. Svizzera. Diritti Comparati [blog], 15-09-2011. Disponible en: www.diritticomparati.it.

- (2013). «Illnes» or «desease»? La Corte di Strasburgo ritorna sulla legislazione svizzera in materia di «fine vita». Diritti Comparati [blog], 24-10-2013. Disponible en: www.diritticomparati.it.

- (2017). Lambert contro Lambert, ovvero la Corte di Strasburgo e la «morale provvisoria». Diritti Comparati [blog], 18-06-2015. Disponible en: www.diritticomparati.it.

Conti, R. (2012). Il diritto alla vita nella giurisprudenza delle Alte Corti. Politica del diritto, 43(4), 555-602.

- (2013). I giudici e il biodiritto. Un esame concreto dei casi difficili e del ruolo del giudice di merito, della Cassazione e della Corti europee. Roma: Aracne.

Crivelli, E. (2012). Koch c. Germania: la Corte di Strasburgo afferma il diritto a vedere esaminata nel merito la richiesta di suicidio assistito del proprio coniuge. Rivistaaic, 4, 1-5.

- (2013). Gross c. Svizzera: la Corte di Strasburgo chiede alla Svizzera nuove e più precise norme in tema di suicidio assistito. Osservatorioaic, 0, 1-5.

D’Aloia, A. (2012). Eutanasia. Enciclopedia del diritto. Milan: Utet.

De Stefani, P. (2010). Dimensioni del biodiritto nella giurisprudenza della corte europea dei diritti umani. Aspetti penalistici. En S. Rodotà y M. Tallacchini (eds.). Trattato di biodiritto. Ambito e fonti del biodiritto (pp. 657-706). Milan: Giuffrè.

Di Carlo A., (2012). A. La scelta di non legiferare in tema di eutanasia: il caso della Svizzera. En A. D’Aloia (ed.). Il diritto alla fine della vita. Napoli: Edizioni Scientifiche Italiane.

Di Lavoro, G. (2019). Aiuto medico a morire e diritto e diritto: per la costruzione di un dibattito pubblico plurale e consapevole. BioLaw Journal - Rivista di BioDiritto, 18(3), 159-177.

Fiano, N. (2020). Il diritto alla dignità nel «fine vita»: la storica e recentissima pronuncia del BVerfG in tema di suicidio assistito. Diritti comparati [blog], 14-42020. Disponible en: www.diriticomparati.it.

Harris, J. y Guarding, C. (2018). Forum: Il caso di Alfie Evans. BioLaw Journal - Rivista di BioDiritto, 2, 5-9.

Hennette-Vauchez, S. (2015). Pourquoi l'affaire Lambert n'en finit pas. BioLaw Journal - Rivista di BioDiritto, 3, 151-155.

Maisto, V. (2011). La Corte EDU dichiara ammissibile un ricorso in tema di eutanasia attiva. Diritto penale contemporaneo [blog], 20-7-2011. Disponible en: www. dirittopenalecontemporaneo.it.

Malfatti, E. (2019). Sui richiami, nell'ordinanza Cappato, alla giurisprudenza della Corte di Strasburgo. Forum di Quaderni Costituzionali, 6, 1-6. 
Parodi, C. (2013a). Una cauta pronuncia della Corte europea in tema di eutanasia attiva. Diritto penal contemporaneo [blog], 19-2-2013. Disponible en: Dirittopenalecontemporaneo.it.

- (2013b). Una Corte divisa su una materia divisiva: una pronuncia di Strasburgo in tema di suicidio assistito. Diritto penal contemporaneo [blog], 6-6-2013. Disponible en: Dirittopenalecontemporaneo.it.

Plebani, M. y Trenti, T. (2002). Linee guida e audit: strumenti di Governo Clinico nell'organizzazione sanitaria. En M. Plebani y T. Trenti (eds.). Praticare il Governo clinico. Qualità, efficacia e professionalità in Medicina (pp. 25-54). Torino: Centro Scientifico Editore.

Poli, L. (2017). Infondatezza manifest... ma solo per alcuni: riflessioni a margine del caso "Charlie Gard». Diritti umani e diritto internazionale, 3, 752-762.

- (2020). La sentenza n. 242 del 2019 della Corte costituzionale alla luce della giurisprudenza di Strasburgo. Osservatorioaic.it, 1, 363-372.

Ragone, G. (2013). Gross c. Svizzera: Un'ulteriore sentenza in tema di eutanasia della Corte di Strasburgo. Quaderni costituzionali, 33(3), 663-668.

Razzano, G. (2014). Dignità nel morire, eutanasia e cure palliative nella prospettiva costituzionale. Torino: G. Giappichelli Editore.

- (2015a). Accanimento terapeutico o eutanasia per abbandono del paziente? Il caso Lambert e la Corte di Strasburgo. BioLaw Journal - Rivista di BioDiritto, 5(3), 169-184.

- (2015b). La sentenza CEDU sul caso Lambert: la Corte di Strasburgo merita ancora il titolo di The Conscience of Europe? Forumcostituzionale [blog], 17-72015. Disponible en: https://bit.ly/3BsKbaR.

Rivera, I. (2015) Il caso Lambert e la tutela della dignità umana come diritto a vivere (e a morire). Quaderni Costituzionali, 2.

Rodotà, S. (2003). Dai diritti sociali ai diritti dell'individuo. Bioetica, 2.

Santone, P. (2015). I custodi dei diritti umani e la tutela della dignità: contrasti di vedute sul diritto a vivere (e a morire) - Corte europea dei diritti dell'uomo (Grand Chamber). Sentenza 5 giugno 2015, ric.46043/2014. Lambert and Others v. France (opinione congiunta parzialmente dissenziente di cinque giudici). DPCE, 1, 295-305.

Schettino, S. (2017). Il diritto di autodeterminazione e la rappresentanza dell'interesse del minore. Brevi note sul (triste...) caso di Charlie Gard. Dirittifon damentali, 2.

Silva, C. (2017). Suicidio assistito in Svizzera. Riflessioni in ordine alla rilevanza penale della condotta di agevolazione. Rivista italiana di diritto e procedura penale, $1,308-321$.

Tega D. (2012). I diritti in crisi. Tra Corti costituzionali e Corte europea di Strasburgo. Milan: Giuffrè.

Tomasi, L. (2012). Art. 8. Diritto al rispetto della vita privata e familiare. En V. Zagrebelsky, P. De Sena y S. Bartole (eds.). Commentario breve alla Convenzione europea per la salvaguardia dei diritti dell'uomo e delle libertà fondamentali (pp. 297-369) Padova: Cedam. 
Tripodina, C. (2004). Il diritto nell'età della tecnica. Il caso dell'eutanasia. Napoli: Jovene.

Venturi, F. (2017). Il principio dei best interests of the child nel caso Gard tra paternalismo, autonomia e indeterminatezza. Focus Human Rights, 3.

Veronesi, P. (2007). Il corpo e la Costituzione. Concretezza dei «casi» e astrattezza della norma. Milan: Giuffrè.

Vigato, E. (2013). Il suicidio assistito in Svizzera: la Corte europea dei diritti dell'uomo «invita» a prendere posizione anche sull'eutanasia delle persone sane. Diritto pubblico comparato ed europeo, 3 .

Villone, M. (2017). La difficile ricerca del miglior interesse di Charlie. Il Manifesto, 16 de julio.

Zagrebelsky, V. (2015). Un dilemma che non si può più ignorare. La Stampa, 6 de junio.

- (2016). La vita privata. L'identità personale, etnica e sociale. L'autonomia e l'integrità psicofisica. En R. Chenal y L. Tomasi (eds.). Manuale dei diritti fondamentali in Europa. Bologna: Il Mulino.

- (2017). Autodeterminazione, suicidio assistito e Convenzione dei diritti umani e delle libertà fondamentali. Associazione Luca Coscioni. Disponible en: www. associazionelucacoscioni.it.

Zambrano, V. (2016). La questione del «fine vita» e il ruolo del giudice europeo: riflessioni a margine del caso Lambert c. Francia. Federalismi.it. Disponible en: www.federalismi.it.

Zanichelli, M. (2011). L'aiuto al suicidio può essere un obbligo degli Stati? Quaderni costituzionali, 31(2), 428-430.

Zuffa, G. Toraldo di Francia, M. (2017). Il piccolo Charlie, le maglie troppo strette dell'inermia. Il Manifesto, 28 de julio. 